\title{
No evidence of a higher 10 year period prevalence of diabetes among 77,885 twins compared with 215,264 singletons from the Danish birth cohorts 1910-1989
}

\author{
I. Petersen • M. M. F. Nielsen • H. Beck-Nielsen • \\ K. Christensen
}

Received: 12 January 2011 /Accepted: 7 March 2011 /Published online: 13 April 2011

(C) Springer-Verlag 2011

\begin{abstract}
Aims/hypothesis Previous Danish twin studies have found a highly increased risk of precursors of type 2 diabetes as well as a higher prevalence of type 2 diabetes among twins compared with singletons. Likewise, small-scale studies of Danish twins have shown that monozygotic twins have a higher risk of developing precursors of type 2 diabetes compared with dizygotic twins. In the present registerbased study, the 10 year period diabetes prevalence in Danish twins is compared with that in a random sample of Danish citizens. Furthermore, the 10 year period prevalence of diabetes in monozygotic twins is compared with that in dizygotic twins.

Methods The study population consisted of twins $(n=77,885)$ identified in the Danish Twin Registry, and a 5\% random sample $(n=215,264)$ from the birth cohorts $1910-1989$. We identified diabetes patients by means of three nationwide Danish health registers.

Results The number of identified diabetes cases among males was $6,677(6.24 \%)$ for singletons vs 2,271 (5.68\%) for twins (difference $=0.56 \%[0.29-0.83 \%])$. The number
\end{abstract}

I. Petersen $(\bowtie) \cdot K$. Christensen

The Danish Twin Registry, Danish Aging Research Center,

University of Southern Denmark,

J. B. Winsløws Vej 9B st.tv.,

5000 Odense C, Denmark

e-mail: ipetersen@health.sdu.dk

M. M. F. Nielsen $\cdot$ H. Beck-Nielsen

Department of Endocrinology and Metabolism,

Odense University Hospital,

Odense, Denmark

\section{K. Christensen}

Department of Clinical Biochemistry and Pharmacology and Department of Clinical Genetics, Odense University Hospital, Odense, Denmark among females was 6,143 (5.67\%) for singletons and 1,722 $(4.54 \%)$ for twins (difference $=1.13 \%$ [0.88-0.38\%]). Restriction to various birth cohorts, known zygosity and known type 2 diabetes did not alter the overall conclusions. The difference between monozygotic twins (males, 5.29\%; females, 4.40\%) and dizygotic twins (males, 5.77\%; females, $4.63 \%$ ) was non-significant.

Conclusions/interpretation Danish twins do not have an increased risk of developing diabetes compared with singletons, and the risk of diabetes among monozygotic twins does not differ from that of dizygotic twins.

Keywords 10 year period prevalence Diabetes . Heritability · Register-based study · Singletons · Twins
Abbreviations
AIC Akaike's information criterion
ATC Anatomical Therapeutic Chemical Classification
System
CPR Central Person Register
DTR Danish Twin Registry
DZ Dizygotic
MZ Monozygotic
osDZ Opposite-sex dizygotic
ssDZ Same-sex dizygotic
UZ Unknown zygosity

\section{Introduction}

The fetal origins hypothesis states that fetal undernutrition in middle-to-late gestation programmes for a higher susceptibility of developing adverse health outcomes such as hypertension, coronary heart diseases, impaired glucose 
tolerance and type 2 diabetes [1]. Birthweight is, though not fully sufficient, an easily obtainable summary measure of fetal growth and has therefore been widely used when investigating the validity of the fetal origins hypothesis. Hence several studies have provided evidence of an inverse association between birthweight and coronary heart disease $[2,3]$, blood pressure [4], and risk of developing type 2 diabetes $[5,6]$. While the association between birthweight and adverse health outcomes in adult life has been confirmed in several studies, the underlying reason for the link between these phenotypes is still under debate. The thrifty phenotype hypothesis claims that poor nutrition in late gestation permanently alters the metabolism, thereby causing a higher susceptibility of developing type 2 diabetes in adult life $[7,8]$. On the other hand, the fetal insulin hypothesis proposes that the inverse association between impaired fetal growth and susceptibility to developing type 2 diabetes in adult life is predominantly driven by genetic confounding (pleiotropy): i.e. common genetic factors affecting both fetal growth and susceptibility to type 2 diabetes [9].

The low birthweight of twins compared with singletons (mean difference, $900 \mathrm{~g}$ ) [10-12] has caused concern that twins per se face a higher risk of developing type 2 diabetes in adult life compared with singletons [13]. Previous smallscale studies of Danish twins drawn from the Danish Twin Registry (DTR) have demonstrated that twins have a higher incidence and prevalence of type 2 diabetes [14] as well as a higher prevalence of precursors of type 2 diabetes [14-16] compared with singletons. It has been argued that these results are caused by factors associated with lower birthweight of twins [17]. Similar results were found in a small study of insulin resistance in prepubertal twins and singletons from New Zealand, [18] while studies of adult Scots did not find evidence of twin-singleton differences in prediabetic disorders $[19,20]$. In a large study of selfreported diabetes among 18,230 Swedish twins from birth cohorts 1926-1958, the authors observe the same overall prevalence of type 2 diabetes as that reported in the general population by the Swedish National Board of Health [21]. Prevalence figures for diabetes in twins stratified for birth cohorts in two Swedish studies [21,22] were similar to that found in a large-scale study based on data from the Finnish Twin Registry [23].

It has been hypothesised that monozygotic (MZ) twins exhibit more features of the metabolic syndrome and type 2 diabetes than dizygotic (DZ) twins [15]. This difference is thought to have its origin in the fact that two-thirds of MZ twins are monochorionic and thus share the source of nutrition in the womb, causing a potentially more adverse intrauterine environment for these fetuses [15]. While only small differences in prevalence of type 2 diabetes are reported in large-scale studies based on data from the
Finnish [23] and Swedish [21, 22] twin registries, a number of small-scale studies of Danish twins provide support for a higher susceptibility of developing type 2 diabetes among MZ compared with DZ twins [16, 24-27]. The results of the small Danish studies may be chance findings due to varying classifications, outcomes and small sample sizes, or they may reflect a real difference between the Nordic countries based on different risk profiles: for example, despite closeness in geography, healthcare and social systems, the life expectancy in Sweden is 3 years longer than in Denmark, mainly because of differences in smoking rates $[28,29]$.

Here we report a nationwide register-based study including 77,885 twins (17,331 MZ, 27,951 same-sex (ss) DZ, 24,917 opposite-sex (os)DZ, and 7,686 of unknown zygosity (UZ)) and a random 5\% sample of the Danish population consisting of 215,264 singletons, all followed for 10 years through national Danish health registers.

\section{Methods}

\section{Materials}

The Danish Twin Registry The DTR comprises more than 80,000 Danish twin pairs from the birth cohorts 18702005. The recruitment procedures for the DTR have been thoroughly described by Skytthe et al. [30]. The twin birth cohorts 1870-2001 registered in the DTR and surviving until the start-up of the Central Person Register (CPR) at 2 April 1968, or born thereafter, have been linked to several administrative databases held at Statistics Denmark.

Zygosity Zygosity determination of the twins is based on mail-back questionnaires of physical similarities; a method that has proven to give rise to a misclassification of less than 5\% [31]. Zygosity information was unknown, because of either missing or contradictory responses to the questionnaire, in $9.9 \%$ of the twin pairs.

$5 \%$ random sample In addition, we have information on a $5 \%$ random sample of each Danish birth cohort from 1870 to 2001 who were all alive and resident in Denmark at the start of the CPR (2 April 1968), or born or immigrated thereafter.

Linkage Linkage between all registries is feasible because of a unique ten-digit personal identification number assigned to all Danish residents at 2 April 1968.

Data In the present study we constrain the data to Danishborn non-emigrated individuals from birth cohorts 19101989, leaving 77,885 twins and 215,264 singletons alive 
and resident in Denmark at 1 January 1997. Birth country was localised by means of the Danish Demographic Database [32] supplemented by information from the CPR when information in the Danish Demographic Database was absent. Identification of Danish residents on 1 January 1997 was based on information on individuals included in the Integrated Database for Labor Market Research 1996, [33] which contains all Danish residents on 1 January the following year.

Identification of diabetes patients For both twins and singletons it is possible to identify all hospitalised patients with a diabetes diagnosis since the start of the National Patient Register in 1977. Additional tracking was made feasible using the Register of Medicinal Product Statistics, [34] which covers all subsidised redeemed prescriptions since 1995 and, from 1997, the Danish National Health Service Register, which holds information on all contacts to general practitioners, specialist doctors, and subsidised treatments conducted by, for example, podiatrists [35]. We have used the procedure [36] introduced by the Danish National Board of Health to identify diabetes patients in the Danish healthcare system from: (1) ICD-10 codes E10, E11, E12, E13, E14, O24, and H360 (www.who.int/ classifications/icd/en/) in the Danish National Patient Register (excluding gestational diabetes [code O244]); (2) the primary healthcare system via the Danish National Health Service Register if a patient had five blood glucose measurements within a calendar year, or two glucose measurements each year for five consecutive years, or a podiatry treatment; and (3) redeemed prescriptions for insulin (Anatomical Therapeutic Chemical Classification System [ATC] code A10A*) or glucose-lowering agents (ATC codes

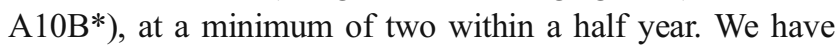
identified all registered occurrences of diabetes within the period 1997-2006 according to these definitions (i.e. in a similar manner to the procedures used by the Danish National Board of Health, we excluded diabetes cases from before all three registries were accessible in 1997).

It is not possible to distinguish between patients with type 1 and 2 diabetes based on information from the Danish Health Registers. However, we identified all patients who had ever redeemed a prescription for oral glucose-lowering agents (ATC codes A10B*) or been assigned a non-insulin dependent diagnosis (E11) as patients suffering from type 2 diabetes. This approach of classifying diabetes into type 1 and type 2 is close to the one used by Iliadou et al. in their study of diabetes in 11,162 Swedish twins [22].

Statistical methods

The 10 year period prevalence of diabetes stratified for 10 year birth cohorts, sex and twin/singleton status as well as zygosity (MZ vs DZ) was calculated. Fisher's exact test was used to test for differences of 10 year period prevalence of diabetes between groups (i.e. equality of 10 year period prevalence of diabetes in twins vs singletons as well as MZ vs DZ).

All analyses were repeated: (1) after restriction to known type 2 diabetes cases; and (2) after exclusion of UZ twins $(9.9 \%)$.

Stata 11 [37] was used for all analyses except for structural equation modelling, which was performed using the Mx software [38].

Validation The Danish National Board of Health has established the Danish National Diabetes Register based on the same registers and methods as the ones used in the present study, and it publishes an annual report on the prevalence of diabetes within the total Danish population [36]. We restricted the sample to individuals alive on 1 January 2007 who had been resident in Denmark during the 10 year period $1997-2007$, leaving $69,118(89.4 \%)$ twins and 183,870 (86.4\%) singletons. We compared the age- and sex-stratified prevalence with the 2009 report from the National Board of Health (reporting diabetes prevalence at 1 January 2007) [36] in order to validate our data and methods.

Heritability estimates To further test the validity of the data we calculated the heritability of 10 year period diabetes prevalence to compare with estimates based on studies of the Finnish Twin Registry. Sex-specific correlations of liability and heritability estimates were calculated for complete MZ and ssDZ pairs. Structural equation modelling techniques based on threshold models and using the Mx software [38] were implemented for the assessment of correlations of liability as well as heritability estimates. Using these models it is assumed that the total variation can be decomposed as $\mathrm{V}=\mathrm{A}+\mathrm{C}+\mathrm{D}+\mathrm{E}$ (A, additive genetic; $\mathrm{C}$, shared environment; $\mathrm{D}$, genetic dominance; and $\mathrm{E}$, non-shared environment). Furthermore, it is assumed that gene-gene and gene-environment interactions are absent. As the ACDE model is under-identified, $\mathrm{C}$ and $\mathrm{D}$ cannot be estimated simultaneously, thus ACE, ADE, and sub-models of these were fitted to the data. Best-fitting models were chosen as those with the lowest Akaike's information criterion $(\mathrm{AIC}=-2 \operatorname{loglikelihood}-2 d f)$.

Informed consent

The study was based on secondary data analyses of register data, hence no informed consent from the participants was needed. The project was approved by the Danish Data Protection Agency (journal number 2007-41-1317). 
Table 1 Number and age of male twins and singletons alive and resident in Denmark on 1 January 1997 and number with diabetes

\begin{tabular}{|c|c|c|c|c|c|c|c|}
\hline \multirow[t]{2}{*}{ Birth cohort } & \multicolumn{3}{|l|}{ Twins } & \multicolumn{4}{|c|}{ Singletons } \\
\hline & $n$ & Age (mean $\pm \mathrm{SD})$ & Diabetes cases, $n(\%)$ & $n$ & Age (mean $\pm \mathrm{SD})$ & Diabetes cases, $n(\%)$ & $p$ value $^{\mathrm{a}}$ \\
\hline 1910-1919 & 675 & $81.4 \pm 2.9$ & $92(13.6)$ & 4,233 & $81.2 \pm 2.7$ & $539(12.7)$ & 0.54 \\
\hline $1920-1929$ & 1,573 & $71.7 \pm 2.8$ & $269(17.1)$ & 8,624 & $71.7 \pm 2.9$ & $1,335(15.5)$ & 0.11 \\
\hline $1930-1939$ & 4,686 & $61.5 \pm 2.8$ & $719(15.3)$ & 11,411 & $61.7 \pm 2.9$ & $1,674(14.7)$ & 0.28 \\
\hline $1940-1949$ & 7,587 & $51.6 \pm 2.8$ & $683(9.0)$ & 17,378 & $51.7 \pm 2.8$ & $1,687(9.7)$ & 0.08 \\
\hline $1950-1959$ & 6,631 & $42.0 \pm 3.0$ & $289(4.4)$ & 17,103 & $42.0 \pm 2.9$ & $797(4.7)$ & 0.33 \\
\hline $1960-1969$ & 7,159 & $32.1 \pm 2.8$ & $140(2.0)$ & 18,165 & $32.0 \pm 2.8$ & $416(2.3)$ & 0.11 \\
\hline $1970-1979$ & 6,103 & $22.1 \pm 2.9$ & $46(0.8)$ & 16,346 & $22.2 \pm 2.8$ & $161(1.0)$ & 0.12 \\
\hline $1980-1989$ & 5,559 & $11.9 \pm 2.9$ & $33(0.6)$ & 13,689 & $11.9 \pm 2.9$ & $68(0.5)$ & 0.44 \\
\hline
\end{tabular}

${ }^{a} p$ value for equal 10 year period diabetes prevalence among twins and singletons (Fisher's exact test)

\section{Results}

We identified 16,813 (5.7\%) diabetes patients, of whom 6,677 were male singletons, 2,271 were male twins, 6,143 were female singletons and 1,722 were female twins. Tables 1 and 2 show the mean values and SD for age and number of individuals alive on 1 January 1997 within 10 year birth cohorts stratified for sex and twin/singleton status for males and females, respectively. The numbers demonstrate that small and non-systematic differences in the age distribution of twins and singletons are present as expected from previous work showing that twins have an adult mortality similar to that of singletons [39]. Percentages of individuals exiting the study population before 2007, because of either death or migration in the period from 1997 to 2007, stratified for 10 year birth cohorts and twin/singleton status, are reported in Fig. 1. The figure illustrates that there are no systematic differences in loss through death and migration between the twin and the singleton populations. Stratification for sex did not alter these conclusions (results not shown.)

The 10 year period prevalence (1997-2006) as well as $95 \%$ CIs of all Danish-born individuals alive on 1 January 1997 stratified for sex, 10 year birth cohorts and twin/singleton status is shown in Fig. 2. The results reveal no difference in 10 year period prevalence between twins and singletons, only a tendency towards a higher 10 year period prevalence of diabetes in twins compared with singletons among men from birth cohorts 1910-1939 and women from birth cohorts 1910-1929. For birth cohorts born after 1940 we find the opposite tendency, but the differences are small and mainly not statistically significant. Figure 3 shows the 10 year period prevalence and 95\% CIs of individuals with known type 2 diabetes stratified for sex, 10 year birth cohorts and twin/singleton status. The results reveal the same pattern as for all diabetes cases (Fig. 2) except that the difference for men in birth cohorts 1920-1929 is now statistically significant (difference is $1.91 \%$ [ $95 \% \mathrm{CI}=0.12-3.70 \%]$ ).

Figure 4 reports the 10 year period prevalence of diabetes stratified by 10 year birth cohorts, sex and zygosity (MZ vs osDZ/ssDZ). The only statistically significant difference in favour of a higher diabetes prevalence among MZ twins compared with DZ twins is found in the male $1980-1989$ birth cohorts ( $1.4 \%$ vs $0.3 \%)$, but based on only 22 diabetic twins. As these patients were 18-28 years of

Table 2 Number and age of female twins and singletons alive and resident in Denmark on 1 January 1997 and number with diabetes

\begin{tabular}{|c|c|c|c|c|c|c|c|}
\hline \multirow[t]{2}{*}{ Birth cohort } & \multicolumn{3}{|l|}{ Twins } & \multicolumn{4}{|c|}{ Singletons } \\
\hline & $n$ & Age $($ mean $\pm \mathrm{SD})$ & Diabetes cases, $n(\%)$ & $n$ & Age $($ mean \pm SD $)$ & Diabetes cases, $n(\%)$ & $p$ value $^{\mathrm{a}}$ \\
\hline 1910-1919 & 1,325 & $81.5 \pm 2.9$ & $180(13.6)$ & 6,789 & $81.5 \pm 2.8$ & $838(12.3)$ & 0.22 \\
\hline $1920-1929$ & 2,123 & $71.9 \pm 2.9$ & $304(14.3)$ & 10,650 & $72.0 \pm 2.9$ & $1,503(14.1)$ & 0.81 \\
\hline $1930-1939$ & 4,097 & $61.6 \pm 2.7$ & $459(11.2)$ & 11,761 & $61.8 \pm 2.9$ & $1,380(11.7)$ & 0.38 \\
\hline 1940-1949 & 6,568 & $51.7 \pm 2.8$ & $399(6.1)$ & 17,043 & $51.8 \pm 2.8$ & $1,105(6.5)$ & 0.26 \\
\hline $1950-1959$ & 5,506 & $42.1 \pm 3.1$ & $153(2.8)$ & 16,432 & $42.1 \pm 2.9$ & $567(3.5)$ & 0.02 \\
\hline $1960-1969$ & 7,223 & $32.1 \pm 2.8$ & $122(1.7)$ & 17,270 & $32.0 \pm 2.8$ & $346(2.0)$ & 0.11 \\
\hline 1970-1979 & 5,692 & $22.1 \pm 2.8$ & $85(1.5)$ & 15,561 & $22.2 \pm 2.8$ & $293(1.9)$ & 0.06 \\
\hline $1980-1989$ & 5,378 & $11.7 \pm 2.9$ & $20(0.4)$ & 12,800 & $11.9 \pm 2.9$ & $111(0.9)$ & $<0.01$ \\
\hline
\end{tabular}

${ }^{\text {a }} p$ value for equal 10 year period diabetes prevalence among twins and singletons (Fisher's exact test) 


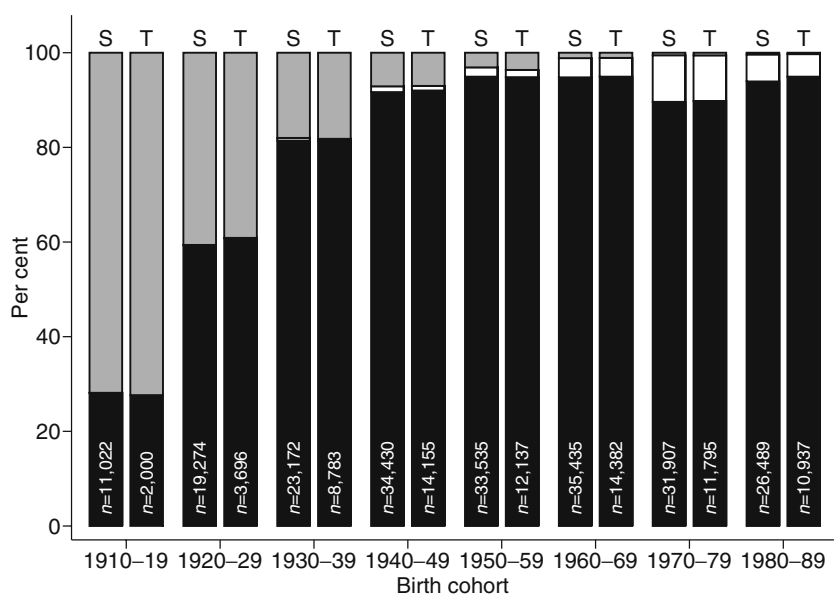

Fig. 1 Proportion of Danish-born twins (T) and singletons (S) present on 1 January 1997 who were alive and had not emigrated during the 10 year period (1997-2006, black), who had emigrated for any period in the 10 year observation time (white), and who had died (grey)

age in 2006, the majority of these cases are patients suffering from type 1 diabetes.

Restricting our sample to individuals resident in Denmark during the 10 year observation period demonstrated similar age and sex-specific prevalence on 1 January 2007 as the ones estimated on the basis of the established Danish National Diabetes Register [36, 40] (results not shown). Thus, we conclude that our data and methods are in agreement with those of the National Board of Health used to create the Danish National Diabetes Register [36].

Re-running the analyses after exclusion of twins with unknown zygosity as well as only including cases with known type 2 diabetes gave nearly identical results and did
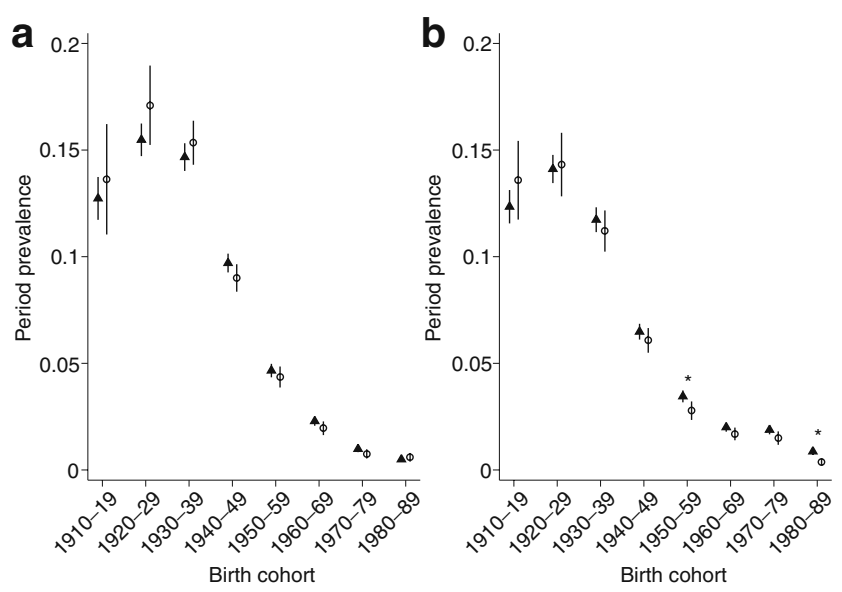

Fig. 2 The 10 year period prevalence of diabetes, stratified for sex, 10 year birth cohort intervals and twin/singleton status in (a) males and (b) females. ${ }^{*} p<0.05$. Population is Danish-born individuals who were alive on 1 January 1997. Singletons, triangles; twins, circles. Vertical bars indicate $95 \%$ CIs

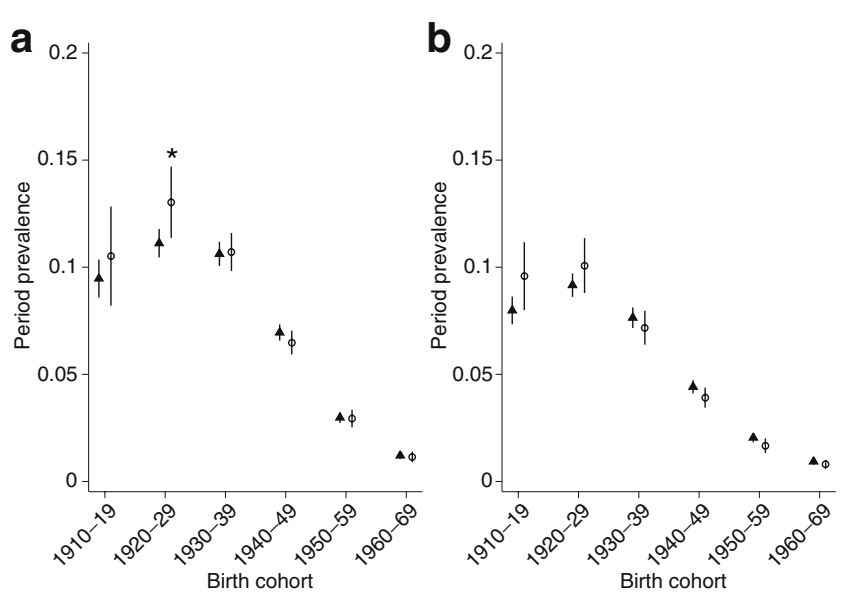

Fig. 3 The 10 year period prevalence of known type 2 diabetes (patients who had ever redeemed a prescription for glucose-lowering agents or been ascribed a non-insulin-dependent diagnosis), stratified for sex, 10 year birth cohort intervals, and twin/singleton status in (a) males and (b) females. ${ }^{*} p<0.05$. Population is Danish-born individuals who were alive on 1 January 1997. Singletons, triangles; twins, circles. Vertical bars indicate $95 \%$ CIs

not alter the overall conclusions of the present study (results not shown).

We repeated the analyses in birth cohorts 1921-1940, including only MZ and ssDZ twins, in order to retrieve results that could be compared directly with results from previous Danish studies of twins and singletons [14, 16, 25-27]. These sub-analyses demonstrated no twin-singleton differences in overall 10 year diabetes prevalence among males (twins, 15.7\%; singletons, 14.9\%; $p=0.23$ ); or females (twins, 12.5\%; singletons, $12.5 \%$; $p=0.98$ ). Neither could we demonstrate any statistically significant difference, despite the large sample size, in 10 year period
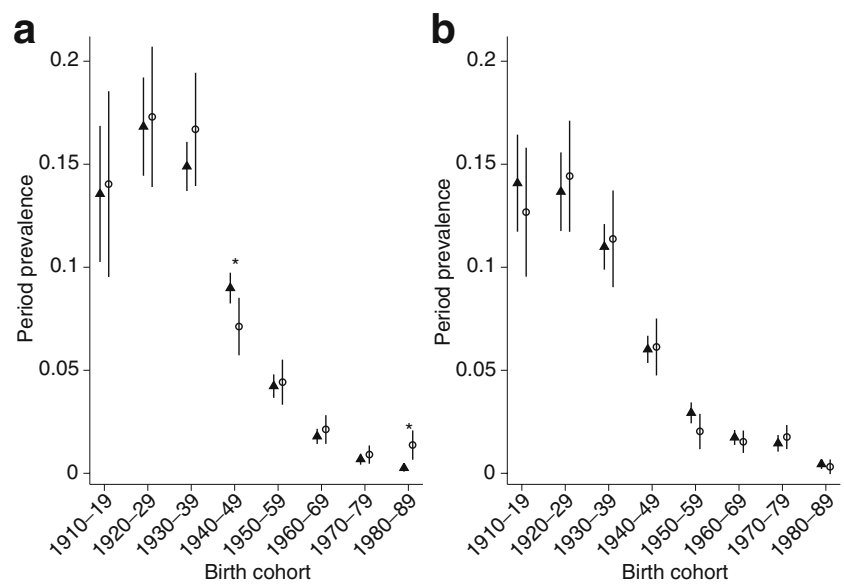

Fig. 4 The 10 year period prevalence of diabetes stratified for sex, 10 year birth cohort intervals, and zygosity (MZ vs osDZ/ssDZ) in (a) males and (b) females. ${ }^{*} p<0.05$. Population is Danish-born individuals who were alive on 1 January 1997. osDZ/ssDZ, triangles; MZ, circles. Vertical bars indicate $95 \%$ CIs 
diabetes prevalence in MZ vs ssDZ twins (males, $16.9 \%$ vs $15.1 \%, p=0.16$; females, $12.9 \%$ vs $12.3 \%, p=0.59$ ).

Heritability estimates Structural equations modelling was carried out on 8,092 MZ pairs (4,124 female and 3,968 male pairs) and 12,557 ssDZ pairs $(6,128$ female and 6,429 male pairs). The sex-specific correlations of liability were significantly higher for $\mathrm{MZ}$ twins than for ssDZ twins (males, 0.79 vs $0.39[p<0.001]$; females, 0.70 vs 0.39 $[p<0.001])$, thus indicating a genetic contribution to the observed variance of diabetes for both sexes. Model-fit statistics as well as heritability estimates for all biometric models are reported in Tables 3 and 4. The AE model demonstrated the best fit for both sexes and the estimated heritability was 0.79 (95\% CI $0.74-0.84)$ for males and slightly lower $(0.71$ [95\% CI $0.64-0.77])$ for females. The heritability estimate of known type 2 diabetes among females was similar to the estimates for all diabetes cases, but was slightly lower for males (0.72 [95\% CI 0.60-0.78]).

\section{Discussion}

In the comparison study of 77,885 twins and 215,264 singletons from the Danish birth cohorts 1910-1989 we did not find evidence of an increased risk of diabetes in twins. Neither did we find any difference of diabetes prevalence between MZ and DZ twins.

Several small-scale studies involving clinical examinations have demonstrated that twins face a higher risk of developing metabolic abnormalities: lower insulin sensitivity of twins compared with singletons in prepubertal children (50 twins and 20 singletons) from New Zealand [18], measures from an OGTT test of 297 twins and 71 singletons from Denmark (birth cohorts 1921-1940) [14], results from clamp examination of 86 twins and 17 agematched spouses from Danish birth cohorts 1931-1940
[16], and measures from OGTTs of $48 \mathrm{MZ}$ twins and 50 singletons from Italy (mean age, 33 years) [41]. Conversely, no evidence of differences in several outcomes within the metabolic syndrome was found in a clinical examination of 131 adult twin pairs and 89 singletons [19, 20].

Johansson et al. studied the prevalence of self-reported type 2 diabetes among 18,442 twins from birth cohorts 1926-1958 and found the same type 2 diabetes prevalence among Swedish same-sex twins (3.2\%) as in the background population [21]. Iliadou et al. estimated a slightly higher type 2 diabetes prevalence (3.7\%) among 11,162 Swedish same-sex twins from birth cohorts 1906-1958 [22]. Likewise, Kaprio et al. identified diabetes cases by means of two national health registers (data on hospital discharges and Registry of the Social Insurance Institution for reimbursement of free-of-charge medication) of 13,888 Finnish same-sex twin pairs born prior to 1958 [23]. The estimated cumulative incidence in the Finnish study was $2.7 \%$. Furthermore, the three studies reported approximately the same prevalence of diabetes in the age range 40-75 years. We estimated the prevalence (based on the cumulative prevalence on 1 January 2007) of diabetes in the same age groups as the two Swedish studies as well as the Finnish study and found significantly higher prevalence $(6.8 \%$ vs $3.7 \%$ in Iliadou et al. [22], 4.9\% vs 3.7\% in Johansson et al. [21], and $6.5 \%$ vs $2.7 \%$ in Kaprio et al. [23]) in our data. The differences persisted throughout the age range. These differences may be due to a higher diabetes prevalence in the Danish population, but more likely the discrepancy is caused by the use of different criteria for defining diabetes cases in the three studies as well as a higher diagnosis frequency and/ or prevalence of type 2 diabetes in more recent years compared with preceding years.

In summary, the results of Danish, Italian and New Zealand small-scale clinical examinations of twins and singletons have demonstrated adverse effects of twin status on outcomes related to type 2 diabetes, but large register

Table 3 Model-fit statistics of 10 year period diabetes prevalence among 8,092 MZ twin pairs and 12,557 ssDZ twin pairs from Danish birth cohorts 1910-1989

\begin{tabular}{|c|c|c|c|c|c|c|c|c|c|c|}
\hline \multirow[t]{2}{*}{ Model-fit statistics } & \multicolumn{5}{|c|}{ Males $^{\mathrm{a}}$} & \multicolumn{5}{|c|}{ Females $^{\mathrm{b}}$} \\
\hline & vs & $\Delta \chi^{2}$ & $\Delta d f$ & AIC & $p$ value & vs & $\Delta \chi^{2}$ & $\Delta d f$ & AIC & $p$ value \\
\hline ACE & $\mathrm{Sat}^{\mathrm{c}}$ & 0.67 & 3 & -5.33 & 0.88 & $\mathrm{Sat}^{\mathrm{c}}$ & 0.01 & 2 & -3.99 & $>0.99$ \\
\hline $\mathrm{ADE}$ & $\mathrm{Sat}^{\mathrm{c}}$ & 0.63 & 3 & -5.37 & 0.89 & $\mathrm{Sat}^{\mathrm{c}}$ & 0.91 & 2 & -3.09 & 0.64 \\
\hline $\mathrm{AE}$ & $\mathrm{ADE}$ & 0.04 & 1 & -7.33 & 0.85 & $\mathrm{ACE}$ & 0.90 & 1 & -5.09 & 0.82 \\
\hline $\mathrm{CE}$ & $\mathrm{ACE}$ & 70.3 & 1 & 63.0 & $<0.01$ & $\mathrm{ACE}$ & 28.2 & 1 & 22.2 & $<0.01$ \\
\hline $\mathrm{E}$ & $\mathrm{AE}$ & 432 & 1 & 423 & $<0.01$ & $\mathrm{AE}$ & 27.3 & 1 & 255 & $<0.01$ \\
\hline
\end{tabular}

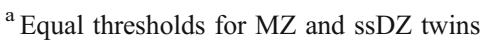

${ }^{\mathrm{b}}$ Unequal thresholds for MZ and ssDZ twins

${ }^{\mathrm{c}}$ Saturated model (model without any constraints) 
Table 4 Heritability estimates of 10 year period diabetes prevalence among 8,092 MZ twin pairs and 12,557 ssDZ twin pairs from Danish birth cohorts 1910-1989

\begin{tabular}{|c|c|c|c|c|c|c|c|c|}
\hline \multirow{2}{*}{$\begin{array}{l}\text { Heritability } \\
\text { estimates } \\
(95 \% \mathrm{CI})\end{array}$} & \multicolumn{4}{|l|}{ Males $^{\mathrm{a}}$} & \multicolumn{4}{|l|}{ Females $^{\mathrm{b}}$} \\
\hline & $a^{2}$ & $c^{2}$ & $d^{2}$ & $e^{2}$ & $a^{2}$ & $c^{2}$ & $d^{2}$ & $e^{2}$ \\
\hline $\mathrm{ACE}$ & $0.79(0.62-0.84)$ & $0.00(0.00-0.14)$ & - & $0.21(0.16-0.26)$ & $0.61(0.39-0.76)$ & $0.09(0.00-0.26)$ & - & $0.30(0.24-0.38)$ \\
\hline $\mathrm{ADE}$ & $0.76(0.44-0.84)$ & - & $0.03(0.00-0.37)$ & $0.21(0.16-0.26)$ & $0.71(0.49-0.77)$ & - & $0.00(0.00-0.23)$ & $0.29(0.23-0.36)$ \\
\hline $\mathrm{AE}$ & $0.79(0.74-0.84)$ & - & - & $0.21(0.16-0.26)$ & $0.71(0.64-0.77)$ & - & - & $0.29(0.23-0.36)$ \\
\hline
\end{tabular}

${ }^{\mathrm{a}}$ Equal thresholds for $\mathrm{MZ}$ and ssDZ twins

${ }^{\mathrm{b}}$ Unequal thresholds for $\mathrm{MZ}$ and ssDZ twins

studies based on Nordic twin registries have not supported these findings. Furthermore, the hypothesis of MZ twins having an increased risk of developing type 2 diabetes compared with DZ twins [15, 24] has not been supported by large-scale register studies based on twin registries [2123, 42]. The conflicting results may be attributable to differences in mortality patterns in the Nordic countries as Denmark lags behind Sweden (for both sexes) and Finland (only for females) in life expectancy [43, 44], even though these differences are partly explained by a higher smoking frequency in Denmark [28, 29]. The present study supports the results of previous register-based studies; only small and mainly statistically non-significant differences of diabetes prevalence in Danish birth cohorts 1910-1989 between twin/singleton and MZ/DZ were found. Furthermore, the Swedish and Finnish studies did not examine the data for possible birth cohort effect on twin-singleton differences. The present study demonstrates that the overall diabetes 10 year period prevalence is similar for twins and singletons. The only differences in multiple testing is a tendency towards a higher diabetes prevalence among twins compared with singletons in older birth cohorts - especially for males - and the reverse tendency is observed in more recent birth cohorts - especially for females. Most of these small differences are statistically non-significant.

The restriction of the analyses to birth cohorts 19211940 revealed a slightly higher, but statistically insignificant, diabetes occurrence among male twins compared with male singletons, but no difference was observed for females. Hence, our study does not support the previous findings of a higher risk of diabetes among twins compared with singletons in birth cohorts 1921-1940. In the multiple testing we only find a statistically non-significant tendency towards a higher 10 year period diabetes prevalence among MZ twins compared with DZ twins in these birth cohorts. The difference is small and statistically insignificant and is not observed in either older birth cohorts (1910-1919) or younger birth cohorts (1940-1979; Fig. 3).

It is well known that twins are, on average, smaller at birth than singletons, thus the concern about long-term health consequences for twins seems reasonable. Size at birth is an insufficient measure of fetal growth; it does not provide any information of the underlying reason or the timing of the occurrence that affected the shifts in the fetal growth. It seems plausible that twins are smaller at birth mainly because of shorter gestational age as well as intra-uterine space restriction rather than undernutrition, and therefore twins have no elevated risk of developing type 2 diabetes.

\section{Heritability}

Heritability of cumulative incidence of type 2 diabetes based on the Finnish Twin Registry has been estimated twice. In 1992 Kaprio et al. [23] demonstrated that additive genetic effects explained $79 \%$ of the variance in females and $69 \%$ in males. When estimated 18 years later, the heritability had changed slightly (females $64 \%$; males $73 \%$ ) [42]. In the present study the estimated heritability of 10 year prevalence of diabetes in the Danish twin population was at a size comparable with data in the Finnish studies: $71 \%$ in females and $79 \%$ in males.

\section{Strengths}

A major strength of the present study is the large sample size, which enables the detection of even small differences as reflected in the narrow confidence intervals. The sample comprises all twins as identified in the Danish Twin Registry together with a 5\% random sample from each birth cohort of all Danish citizens. The study is based on register data, thus eliminating selection bias due to non-response and enabling complete follow-up for non-emigrated $(n=283,247$ [96.6\%]) Danes from the birth cohorts 1910-1989.

\section{Limitations}

Our case group consisted of individuals with type 1 and type 2 diabetes as it is not possible to discriminate effectively between the two types based on the registries used by the Danish National Board of Health and in this study. However, patients with type 1 diabetes only comprise $5-10 \%$ of all diagnosed diabetes cases [45] and 
the conclusions did not alter when we repeated the analyses for a subgroup of those known to have type 2 diabetes (namely those who had ever received glucose-lowering medical treatment and/or been assigned the diagnosis noninsulin dependent diabetes at discharge from hospital). Hence, it is unlikely that our results are biased by the presence of type 1 diabetic patients in the case sample.

Type 2 diabetes is known to be severely underdiagnosed, thus it is estimated that approximately $60 \%$ of individuals suffering from type 2 diabetes are unaware of their disease [46]. However, there is no reason to expect that the twin population should be more under-diagnosed than the singleton population. On the contrary, it could be reasoned that a co-twin of a diagnosed twin would be more inclined to consult the healthcare system than a singleton with a younger/older sibling who had received a diagnosis, thus inducing a higher diagnosis frequency among twins compared with singletons. This bias would induce an artificial overestimation of the twin-singleton difference in the direction of a higher prevalence among twins.

There was no physical examination of the individuals included in our study. Hence, we cannot study the occurrence of precursors for type 2 diabetes within the range of the metabolic syndrome. However, a higher 10 year occurrence of prediabetic conditions within the twin population would be expected to be followed by a higher 10 year period prevalence of type 2 diabetes.

Left truncation of the data could bias the results as identification of diabetes cases in our study relied on survival until the three health registers were up and running (1 January 1997). However, as is evident from Fig. 1, the mortality patterns for twins and singletons are similar, and therefore the left truncation is unlikely to affect twins and singletons differently.

Register-based information on birthweight in Danish birth cohorts is only obtainable from 1979 onwards. We examined the association between diabetes and birthweight for the birth cohorts 1979-1989 (results not shown); 266 (0.64\%) diabetes cases were identified from 41,294 individuals with known birthweights. There was no evidence of an inverse relationship between birthweight and risk of diabetes in a cohort analysis nor in an intra-pair twin analysis. However, the absent association between birthweight and diabetes prevalence may very well be due to the young ages (18-28 years at the end of the observation period) of the individuals in our study.

The Danish national registers used for the present study do not facilitate a determination of the date of diagnosis which again is a proxy for the time of the onset of the disease. Thus, we were not able to perform regression analyses in order to estimate rate ratios.

We had zygosity information for $90 \%$ of the twin pairs, but the results were nearly identical after exclusion of the
UZ twins. Likewise, restricting the case sample to known type 2 diabetes cases did not change the conclusions.

\section{Conclusion}

Based on the present study of 77,885 twins from birth cohorts 1910-1989 registered in the Danish Twin Registry and surviving until 1 January 1997 together with a 5\% random sample of the background population $(n=215,264)$, we conclude that only small and statistically non-significant differences are observed in the 10 year period prevalence of diabetes between these two populations. No differences between MZ and DZ twins were observed. We observe a tendency towards a higher 10 year diabetes prevalence among twins compared with singletons in the older birth cohorts but the differences are statistically non-significant despite the large sample sizes.

Acknowledgements Part of this work was supported by and carried out within the European Union-funded Network of Excellence LifeSpan (FP6 036894).

Duality of interest The authors declare that there is no duality of interest associated with this manuscript.

\section{References}

1. Barker DJP (1998) Mothers, babies and health in later life, 2nd edn. Churchill Livingstone, Edinburgh

2. Barker DJ (1995) Fetal origins of coronary heart disease. BMJ 311:171-174

3. Huxley R, Owen CG, Whincup PH et al (2007) Is birth weight a risk factor for ischemic heart disease in later life? Am J Clin Nutr $85: 1244-1250$

4. Huxley RR, Shiell AW, Law CM (2000) The role of size at birth and postnatal catch-up growth in determining systolic blood pressure: a systematic review of the literature. J Hypertens $18: 815-831$

5. Harder T, Rodekamp E, Schellong K, Dudenhausen JW, Plagemann A (2007) Birth weight and subsequent risk of type 2 diabetes: a metaanalysis. Am J Epidemiol 165:849-857

6. Whincup PH, Kaye SJ, Owen CG et al (2008) Birth weight and risk of type 2 diabetes: a systematic review. JAMA 300:2886-2897

7. Hales CN, Barker DJ (1992) Type 2 (non-insulin-dependent) diabetes mellitus: the thrifty phenotype hypothesis. Diabetologia 35:595-601

8. Hales CN, Barker DJ (2001) The thrifty phenotype hypothesis. Br Med Bull 60:5-20

9. Hattersley AT, Tooke JE (1999) The fetal insulin hypothesis: an alternative explanation of the association of low birthweight with diabetes and vascular disease. Lancet 353:1789-1792

10. Liu YC, Blair EM (2002) Predicted birthweight for singletons and twins. Twin Res 5:529-537

11. Christensen K, Petersen I, Skytthe A, Herskind AM, McGue M, Bingley P (2006) Comparison of academic performance of twins and singletons in adolescence: follow-up study. BMJ 333:1095 
12. Loos RJ, Derom C, Derom R, Vlietinck R (2005) Determinants of birthweight and intrauterine growth in liveborn twins. Paediatr Perinat Epidemiol 19(Suppl 1):15-22

13. Hales CN, Desai M, Ozanne SE (1997) The thrifty phenotype hypothesis: how does it look after 5 years? Diabet Med 14:189-195

14. Poulsen P, Grunnet LG, Pilgaard K et al (2009) Increased risk of type 2 diabetes in elderly twins. Diabetes 58:1350-1355

15. Vaag A, Poulsen $P$ (2007) Twins in metabolic and diabetes research: what do they tell us? Curr Opin Clin Nutr Metab Care 10:591-596

16. Poulsen P, Vaag A (2006) The intrauterine environment as reflected by birth size and twin and zygosity status influences insulin action and intracellular glucose metabolism in an age- or time-dependent manner. Diabetes 55:1819-1825

17. Grunnet L, Vielwerth S, Vaag A, Poulsen P (2007) Birth weight is nongenetically associated with glucose intolerance in elderly twins, independent of adult obesity. J Intern Med 262:96-103

18. Jefferies CA, Hofman PL, Knoblauch H, Luft FC, Robinson EM, Cutfield WS (2004) Insulin resistance in healthy prepubertal twins. J Pediatr 144:608-613

19. Tuya C, Mutch WJ, Haggarty P et al (2006) The influence of birth weight and genetic factors on lipid levels: a study in adult twins. Br J Nutr 95:504-510

20. Tuya C, Mutch WJ, Broom I, Campbell DM, McNeill G (2003) Size at birth, fasting glucose and insulin levels and insulin resistance in adult twins. Twin Res 6:302-306

21. Johansson S, Iliadou A, Bergvall N et al (2008) The association between low birth weight and type 2 diabetes: contribution of genetic factors. Epidemiology 19:659-665

22. Iliadou A, Cnattingius S, Lichtenstein P (2004) Low birthweight and type 2 diabetes: a study on 11,162 Swedish twins. Int J Epidemiol 33:948-953

23. Kaprio J, Tuomilehto J, Koskenvuo M et al (1992) Concordance for type 1 (insulin-dependent) and type 2 (non-insulin-dependent) diabetes mellitus in a population-based cohort of twins in Finland. Diabetologia 35:1060-1067

24. Poulsen P, Vaag A (2001) Glucose and insulin metabolism in twins: influence of zygosity and birth weight. Twin Res 4:350-355

25. Poulsen P, Levin K, Beck-Nielsen H, Vaag A (2002) Agedependent impact of zygosity and birth weight on insulin secretion and insulin action in twins. Diabetologia 45:1649-1657

26. Poulsen P, Vaag A, Beck-Nielsen H (1999) Does zygosity influence the metabolic profile of twins? A population based cross sectional study. BMJ 319:151-154

27. Poulsen P, Wojtaszewski JF, Richter EA, Beck-Nielsen H, Vaag A (2007) Low birth weight and zygosity status is associated with defective muscle glycogen and glycogen synthase regulation in elderly twins. Diabetes 56:2710-2714

28. Juel K (2008) Life expectancy and mortality in Denmark compared to Sweden. What is the effect of smoking and alcohol? Ugeskr Laeger 170:2423-2427 (article in Danish)

29. Jacobsen R, Keiding N, Lynge E (2006) Causes of death behind low life expectancy of Danish women. Scand J Public Health 34:432-436

30. Skytthe A, Kyvik K, Holm NV, Vaupel JW, Christensen K (2002) The Danish Twin Registry: 127 birth cohorts of twins. Twin Res $5: 352-357$
31. Christiansen L, Frederiksen H, Schousboe K et al (2003) Age- and sex-differences in the validity of questionnaire-based zygosity in twins. Twin Res 6:275-278

32. Petersen JK (2000) The Danish Demographic Database-longitudinal data for advanced demographic methods: 1-28. Available from www.dst.dk/upload/demographic_guide.pdf. Accessed 11 February 2011

33. Emerek R, Hansen PV, Leth-Sorensen S (1990) Documentation of the Danish Database for Labor Market Research: 1-50. Available from http://dst.dk/upload/hovedrapport.pd. Accessed 11 February 2011 (report in Danish)

34. Danish Medicines Agency. Documentation of Register of Medical Product Statistics. Available from www.dkma.dk/1024/visUKLSArtikel. asp?artikelID=10895. Accessed 1 February 2010 (documents in Danish)

35. Danish National Board of Health. Documentation of the Danish Health Insurance Register. Available from www.sst.dk/Indberetning $\% 20 \mathrm{og} \%$ 20statistik/Sundhedsstyrelsens \%20registre/Sygesikringsregister.aspx. Accessed 20 March 2010

36. The National Board of Health (2009) Det Nationale Diabetesregister, 2007:1-10. Available from www.sst.dk/publ/tidsskrifter/ nyetal/pdf/2009/01_09.pdf. Accessed 11 February 2011 (document in Danish)

37. StataCorp. (2009) Stata: Release 11. Statistical software. StataCorp LP, College Station, TX

38. Neale M, Boker SM, Xie G, Maes HH (2003) Mx: Statistical modelling, 6th edn. Department of Psychiatry, Medical College of Virginia, Richmond

39. Christensen K, Vaupel JW, Holm NV, Yashin AI (1995) Mortality among twins after age 6: fetal origins hypothesis vs twin method. BMJ 310:432-436

40. Carstensen B, Kristensen JK, Ottosen P, Borch-Johnsen K (2008) The Danish National Diabetes Register: trends in incidence, prevalence and mortality. Diabetologia 51:2187-2196

41. Bo S, Cavallo-Perin P, Ciccone G, Scaglione L, Pagano G (2001) The metabolic syndrome in twins: a consequence of low birth weight or of being a twin? Exp Clin Endocrinol Diab 109:135-140

42. Lehtovirta M, Pietilainen KH, Levalahti E et al (2010) Evidence that BMI and type 2 diabetes share only a minor fraction of genetic variance: a follow-up study of 23,585 monozygotic and dizygotic twins from the Finnish Twin Cohort Study. Diabetologia 53:1314-1321

43. World Health Organization (2001) World health report 2001:1-78. Available from www.who.int/whr/2001/en/whr01_en.pdf. Accessed 11 February 2011

44. Andreev KF (2002) Evolution of the Danish population from 1835 to 2000. Odense monographs on population aging 9. Odense University Press, Odense

45. Forouhi NG, Merrick D, Goyder E et al (2006) Diabetes prevalence in England, 2001-estimates from an epidemiological model. Diabet Med 23:189-197

46. Glumer C, Jorgensen T, Borch-Johnsen K (2003) Prevalences of diabetes and impaired glucose regulation in a Danish population: the Inter99 Study. Diabetes Care 26:2335-2340 